\title{
THE JANUARY MEETING IN SAN ANTONIO
}

The eighty-second annual meeting of the American Mathematical Society was held in San Antonio, Texas, from Thursday, January 22 through Sunday, January 25, 1976. All the sessions were held in the San Antonio Convention Center. There were 2841 registrants, including 2353 members of the Society.

The forty-ninth Josiah Willard Gibbs Lecture was presented by Arthur S. Wightman, Department of Physics, Princeton University. The title of his lecture was Nonlinear functional analysis and some of its applications in quantum field theory. He was introduced by the President of the Society, Lipman Bers.

The Colloquium Lectures were delivered by I. M. Singer of Massachusetts Institute of Technology and the Institute for Advanced Study. His subject was Connections between analysis, geometry, and topology. The presiding officers at the four lectures in the series were Lipman Bers, John W. Milnor, Richard S. Palais, and Richard L. Bishop.

By invitation of the Committee to Select Hour Speakers for Summer and Annual Meetings there were eleven invited one-hour addresses. The speakers, their institutions, and the titles of their talks were as follows: Peter L. Duren, University of Michigan, Coefficients of univalent functions; Edwin E. Floyd, University of Michigan, Equivariant topology as the study of actions of topological categories; Stephen M. Gersten, University of Utah, $K$-theory of rings; David M. Goldschmidt, University of California, 2-local subgroups of simple groups; Arshag B. Hajian, Northeastern University, Transformations without finite invariant measure; Melvin Hochster, Purdue University, Some applications of the Frobenius in characteristic zero; Donald A. Martin, Rockefeller University, Recent results on infinite games; Peter May, University of Chicago, $A$ survey of infinite loop space theory; Charles F. Miller III, Princeton University, Groups, logic, and embeddings; Walter Noll, Carnegie-Mellon University, Concrete applications, and a new foundation, of abstract differential geometry; Frank L. Spitzer, Cornell University, Time evolution of one-dimensional systems whose equilibrium state is a renewal process.

The presiding officers at these eleven hour lectures were Alexandra Bellow, William W. Boone, David G. Bourgin, Morton L. Curtis, Richard J. Duffin, Robert M. Fossum, Daniel Gorenstein, James A. Jenkins, Carl G. Jockusch, Franklin P. Peterson, and Daniel W. Stroock.

By invitation of the same committee there were twenty-two special sessions of selected twenty-minute papers.

Robert E. Beck of Villanova University and Bernard Kolman of Drexel University organized a special session on Computers in the Study of Nonassociative Rings and Algebras. The speakers were Robert E. Beck, Johan G. F. Belinfante, Charles W. Conatser, Stig Flodmark, Irvin Roy Hentzel, Erwin Kleinfeld, Mark Krusemeyer, Eugene M. Luks, Lawrence Wos, and Hans J. Zassenhaus.

Klaus R. Bichtler of the University of Texas at Austin organized a special 
session on Applications of Vector Measures. The speakers were A. T. Bharucha-Reid, Mark J. Christensen, Joseph Diestel, Victor Goodman, HuiHsiung Kuo, Daniel R. Lewis, Vidyadhar S. Mandrekar, Pesi R. Masani, Brockway McMillan, Michel Metivier, Victor J. Mizel, M. Ann Piech, Reese T. Prosser, Louis Sucheston, Kondagunta Sundaresan, Lawrence E. Thomas, and J. Jerry Uhl, Jr.

Louis Brickman of the State University of New York at Albany organized a special session on Univalent Functions. The speakers were Roger W. Barnard, Douglas M. Campbell, Harry B. Coonce, Paul J. Eenigenburg, Carl H. Fitzgerald, David J. Hallenbeck, James A. Jenkins, William E. Kirwan II, Frank R. Keogh, Albert E. Livingston, John L. Lewis, Thomas H. Mac Gregor, Sanford S. Miller, James W. Noonan, Roger N. Pederson, John R. Quine, Jr., Glenn E. Schober, Herb Silverman, Ted J. Suffridge, and David E. Tepper.

Donald J. Brown of Yale University organized a special session on Mathematical Economics. The speakers were Robert M. Anderson, Pradeep Dubey, Geoffrey Heal, Stephen Schecter, and Yieh-Hei Wan.

Charles R. DePrima of California Institute of Technology organized a special session on Functional Analytical Methods for Nonlinear Partial Differential Equations. The speakers were Stuart S. Antman, Jerry L. Bona, Felix E. Browder, B. Clay Burch, Murray R. Cantor, Michael G. Crandall, Ronald J. DiPerna, Lawrence C. Evans, Joseph W. Jerome, John W. Neuberger, W. V. Petryshyn, Paul H. Rabinowitz, Duane P. Sather, and David H. Sattinger.

Samuel Gitler of the Instituto Politecnico Nacional in Mexico City organized a special session on Homotopy Theory. The speakers were Donald M. Davis, R. James Milgram, Douglas C. Ravenel, Victor Snaith, and P. Emory Thomas. In addition there were several periods of informal discussion.

Samuel I. Goldberg of the University of Illinois at Urbana-Champaign organized a special session on Curvature and Analysis. The speakers were Michael J. Cowen, Kyung T. Hahn, Zvi Har'El, Toru Ishihara, Peter Kierman, Myung He Kwack, Josephine M. Mitchell, Nicholas C. Petridis, Jonathan Sacks, Jaak Vilms, and R. O. Wells, Jr.

Edward L. Green of the University of Illinois at Urbana-Champaign organized a special session on Representations of Rings and Algebras. The speakers were Shimson A. Amitsur, Hyman Bass, Vlastimil Dlab, Kent R. Fuller, Robert Gordon, William H. Gustafson, Arun V. Jategaonkar, Lawrence S. Levy, Maria Inés Platzeck, Murray M. Schacher, Lance W. Small, and Robert B. Warfield, Jr.

Arthur M. Jaffe of Harvard University organized a special session entitled Crash Course on Quantum Field Theory. The speakers were Charles Burnap, Jurg Fröhlich, Ira Herbst, Arthur M. Jaffe, Abel Klein, Oliver A. McBryan, Edward Nelson, Konrad Osterwalder, Jay S. Rosen, Thomas Spencer, and Garrett S. Sylvester.

H. Elton Lacey of the University of Texas at Austin organized a special session on Banach Spaces. The speakers were Dale E. Alspach, Grahame Bennett, Simon J. Bernau, William J. Davis, Leonard E. Dor, James N. Hagler, Robert E. Huff, Robert C. James, William B. Johnson, Peter D. 
Morris, Edward W. Odell, A. Pelczyński, Haskell P. Rosenthal, and Thomas W. Starbird.

Lee Lorch of York University organized a special session on Special Functions: Sources, Applications, and Current Developments. The speakers were William Roy Allaway, Felix M. Arscott, Richard A. Askey, Charles P. Boyer, Bille C. Carlson, Iswar C. Chakravarty, Joaquin B. Diaz, James A. Donaldson, Loyal Durand, Charles F. Dunkl, George Gasper, Jr., Emil Grosswald, Andrew P. Guinand, Deborah T. Haimo, Velmer B. Headley, Mourad E. H. Ismail, Nicholas D. Kazarinoff, Yudell L. Luke, Willard Miller, Jr., Benjamin Muchenhoupt, Martin E. Muldoon, Thomas J. Osler, Lowell Schoenfeld, Neil J. A. Sloane, Kusum K. Soni, Frank Stenger, James D. Talman, Riho Terras, William F. French, Jet Wimp, and Kurt Bernardo Wolf. In addition there was a discussion period chaired by Elias M. Stein.

G. G. Lorentz and L. L. Schumaker of the University of Texas at Austin organized a special session on Algebras of Analytic Functions. This session consisted of a talk by A. G. Vituškin and an informal discussion period chaired by $R$. O. Wells, Jr.

Richard K. Miller of Iowa State University and John A. Nohel of the University of Wisconsin organized a special session on Volterra Integral Equations. The speakers were Fred G. Brauer, Dennis W. Brewer, Kenneth B. Hannsgen, Terry L. Herdman, Thomas Kiffe, Jacob J. Levin, Stig-Olof Londen, Michael E. Lord, Richard C. Mac Camy, Richard K. Miller, Victor J. Mizel, Peter E. Ney, John A. Nohel, Chris Rorres, Carol Carter Shilepsky, Marshall Slemrod, and Robert L. Wheeler.

Karl K. Norton of Boulder, Colorado organized a special session on Number Theory. The speakers were Harvey Cohn, Harold G. Diamond, Andrew G. Earnest, P. D. T. A. Elliott, Paul Erdös, Michael D. Fried, Janos Galambos, Dennis A. Garbanati, Donald G. Hazlewood, Douglas A. Hensley, J. S. Hsia, Richard H. Hudson, William Messing, Carlos J. Moreno, Karl K. Norton, Andrew M. Odlyzko, Charles F. Osgood, Walter V. Philipp, J. Ian Richards, Jeffrey O. Vaaler, and Hans J. Zassenhaus.

Elmor L. Peterson of Northwestern University organized a special session on Mathematical Programming Theory. The speakers were Richard W. Cottle, Richard J. Duffin, B. Curtis Eaves, Fred W. Glover, Alan J. Goldman, Peter L. Hammer, Te Chiang Hu, Ellis L. Johnson, Victor L. Klee, Elmor L. Peterson, Stephen M. Robinson, Gerald L. Thompson, Robert M. Thrall, Christopher J. Witzgall, and Sanjo Zlobec. In addition there was a brief memorial session for the late Delbert R. Fulkerson, who had been scheduled to be one of the speakers.

Nestor M. Riviere of the University of Minnesota organized a special session on Variational Inequalities and Related Topics. The speakers were William K. Allard, Felix E. Browder, Luis A. Caffarelli, Michael G. Crandall, Avner Friedman, Johannes C. C. Nitsche, and Tsuan Wu Ting.

J. Barkley Rosser of the University of Wisconsin organized a special session on Uses of the Computer in Teaching Mathematics Courses. The speakers were Garrett Birkhoff, William S. Dorn, Roger A. Horn, J. Barkley Rosser, and David A. Smith.

Bruce L. Rothschild of the University of California at Los Angeles and 
Ronald L. Graham of Bell Telephone Laboratories organized a special session on Extremal Problems for Finite Sets. The speakers were Thomas C. Brown, Fan R. K. Chung, George F. Clements, Paul Erdös, Curtis Greene, Andras Hajnal, Charlotte H. T. Huang, David Lubell, George B. Purdy, Navin M. Singhi, and Da-Lun Wang.

Arthur Schlissel of John Jay College of Criminal Justice of the City University of New York organized a special session on How Does One Write a History of Mathematics? The speakers were Philip J. Davis, Harold M. Edwards, Jr., Reuben Hersh, Philip S. Jones, Elaine H. Koppelman, Uta C. Merzbach, David L. Outcalt, Henry S. Tropp, and Raymond L. Wilder.

John L. Selfridge of Northern Illinois University organized a special session on Computations and Algorithms in Number Theory. The speakers were Itshak Borosh, Rene DeVogelaere, Earl F. Ecklund, Jr., Richard K. Guy, Vera Pless, Daniel Shanks, Audrey A. Terras, Samuel S. Wagstaff, Jr., Hugh L. Williams, and Marvin C. Wunderlich.

Olga Taussky Todd of California Institute of Technology organized a special session on Integral Matrices in Algebra and Number Theory. The speakers were Joseph E. Carroll, Harvey Cohn, George E. Cooke, Dennis H. Garbanati, Anthony V. Geramita, Larry J. Gerstein, Marshall Hall, Jr., J. S. Hsia, Mark Krusemeyer, Derrick H. Lehmer, Wilhelm Plesken, Michael Singer, Stephen V. Ullom, Wilberd van der Kallen, and Hans J. Zassenhaus.

Paul M. Weichsel of the University of Illinois at Urbana-Champaign organized a special session on Varieties of Algebraic Structures. The speakers were Seymour Bachmuth, Bernhard Banaschewski, Günter Bruns, Stanley N. Burris, Trevor Evans, Ralph S. Freese, George A. Grätzer, Ralph N. McKenzie, Jay I. Miller, Evelyn M. Nelson, Walter D. Neumann, Don L. Pigozzi, Paul M. Weichsel, Kenneth W. Weston, and James J. Woeppel.

There were 61 sessions of contributed ten-minute papers, for which the following persons served as presiding officers: Oliver G. Aberth, William K. Allard, Paul T. Bateman, Gerald A. Beer, Colin Bennett, Earl R. Berkson, Simon J. Bernau, Manuel P. Berriozabal, Colin R. Blyth, William W. Boone, Itshak Borosh, Abe Charnes, E. Ward Cheney, David K. Cohoon, Robert F. Craggs, James A. Donaldson, Amassa C. Fauntleroy, Walter Gautschi, David M. Goldschmidt, Deborah T. Haimo, Arshag B. Hajian, Mark P. Hale, Jr., Japheth Hall, Jr., Richard W. Hamming, Terry L. Herdman, Arthur M. Hobbs, Robert C. James, William E. Kirwan II, Erwin Kleinfeld, Dana May Latch, Eugene H. Lehman, Peter A. Loeb, Donald A. Martin, J. Peter May, Josephine M. Mitchell, M. Susan Montgomery, Arje Nachman, Francis J. Narcowich, Carla C. Neaderhouser, Peter J. Nyikos, Edward W. Odell, William J. Pervin, Cheryl Peterson, Hala O. Pflugfelder, Charles R. Powder, George B. Purdy, Irving Reiner, Argelia V. Rodriquez, William Rundell, Herb Silverman, Ruth Silverman, Robert C. Sine, Robert Speiser, Alvin I. Thaler, P. Emory Thomas, Tsuan Wu Ting, J. Jerry Uhl, Jr., Karen K. Uhlenbeck, Lewis E. Ward, Jr., R. O. Wells, Jr., Arthur S. Wightman, Marvin C. Wanderlich. Of the 558 ten-minute papers scheduled in the program, 47 were withdrawn, so that 511 ten-minute papers were actually presented.

There was one poster session for contributed papers. Of the 14 papers scheduled for this session, two were withdrawn, so that 12 contributed papers were actually presented by the poster method. 
The Oswald Veblen Prize in Geometry was awarded to Professor William P. Thurston for his work on foliations and to Professor James Simons for his work on minimal varieties and characteristic forms.

The Council met on January 21 in the LaVista room of the Hilton Palacio del Rio.

The Council reaffirmed its affiliation with the American Association for the Advancement of Science and elected Professor Orville Harrold to represent the Society in Section A.

The Council continued its discussion of the situation of membership by reciprocity with two decisions, one to abolish reciprocity agreements and the other to establish a new membership category, "foreign member". This is a category for which certain individuals may be eligible and which they may then elect. It carries all privileges except voting rights, with reduced dues. To carry out the decision requires an amendment to the bylaws, to be offered in due course.

The Council endorsed the following statement:

The Society should urge research oriented departments to offer unemployed mathematicians, and mathematicians in jobs with no research facilities, opportunities to remain associated with the research community. This can be done by offering such mathematicians nominal, unpaid research appointments which would provide office space (when feasible) and access to the library as well as an opportunity to participate in seminars and, in general, interact with members of the department.

The Council passed a procedural resolution recommending two resolutions for consideration by the Business Meeting. The account of the substantive resolutions is given in the report of the business meeting below.

The Business Meeting took place on January 23, 1976 at 4:00 P.M. in the Theatre in the Convention Center, with President Bers presiding. Professor Bers introduced the parliamentarian, Colonel F. A. Pillet.

The Secretary reported on the election of 1975. Candidates are listed in this Bulletin, 81, 1058, and 82, 475. All candidates for noncontested positions were elected. In particular, the President-elect is R. H. Bing. Those elected to be vice president were Mary W. Gray and Louis Nirenberg, and those elected to be member-at-large of the Council were Hugo Rossi, Lee A. Rubel, Barry Simon, Daniel Waterman, and Guido L. Weiss.

The Secretary reported on various actions of the Council, as detailed above.

The Business Meeting of August 21, 1975 had placed on the agenda of this Business Meeting the following resolution:

This meeting of the AMS deplores the actions taken by the government of the Soviet Union in depriving those mathematicians who have applied to emigrate from the USSR of their positions within the mathematical community of the USSR. We urge the Soviet government to grant them exit visas and to allow them to function as mathematicians until their visas are granted.

We request the President of the AMS to communicate our position on this matter to appropriate Soviet and American officials and to make appeals in behalf of individual Soviet mathematicians who are thus affected.

After brief debate the resolution was passed. 
The Business Meeting received a recommendation from the Council that it consider a resolution not notified in advance to the membership. The resolution was read, accepted as an item of business by four-fifths of the members present and voting (see Article X, Section 1 of the Bylaws), and amended by adding italicized words. The text then debated was the following:

This Business Meeting of the American Mathematical Society, concerned by reports that the esteemed Uruguayan mathematician Jose Luis Massera is in prison and has been held for a considerable period without trial, states its concern for his health and well-being, and calls for his release and the protection of his human rights.

The resolution was passed.

The Business Meeting received a second recommendation from the Council that it consider a resolution not notified in advance to the membership. The resolution was read and accepted by four-fifths of the members present and voting. The text was as follows:

This Business Meeting of the American Mathematical Society calls for the release from prison of Professor of Mathematics, L. A. Ladyženskii of the University of Riga.

The resolution was passed.

The question was raised by Robert $M$. Thrall whether political questions are a proper concern of this Society. The President noted that the general issue has been referred for consideration to the Committee on Principles and Procedures.

The meeting was adjourned at 5:05 P.M.

Bethlehem, Pennsylvania

Everett Pitcher Secretary

PaUl T. BAteman

URBANA, ILLINOIS Associate Secretary

\section{THE MARCH MEETING IN TALLAHASSEE}

The seven hundred thirty-second meeting of the American Mathematical Society was held at the Florida Agricultural and Mechanical University in Tallahassee, Florida, March 4-5, 1976. There were 157 registrants including 141 members of the Society.

By invitation of the Committee to Select Hour Speakers for the Southeastern Sectional Meetings, hour addresses were given by B. J. Ball of the University of Georgia, L. Carlitz of Duke University, and R. Kalman from the University of Florida. Professor Marion Tinsley introduced Professor Carlitz who talked about Functions and correspondences in a finite field. Professor James C. Cantrell introduced Professor Ball who talked about Geometric topology and shape theory, and Professor A. R. Bednarek introduced Professor Kalman who spoke about The global theory of the Riccati equation.

There were four special sessions held at this meeting. Each of these special sessions was split into two parts, half held on Thursday afternoon and the other half held on Friday morning. Professor Heron Collins of Louisiana 